\title{
Pseudomonas putida mt-2 tolerates reactive oxygen species generated during matric stress by inducing a major oxidative defense response
}

Nanna B. Svenningsen ${ }^{1}$, Danilo Pérez-Pantoja ${ }^{2}$, Pablo I. Nikel ${ }^{2}$, Mette H. Nicolaisen ${ }^{1}$, Víctor de Lorenzo ${ }^{2}$ and Ole Nybroe ${ }^{1 *}$

\begin{abstract}
Background: Soil bacteria typically thrive in water-limited habitats that cause an inherent matric stress to the cognate cells. Matric stress gives rise to accumulation of intracellular reactive oxygen species (ROS), which in turn may induce oxidative stress, and even promote mutagenesis. However, little is known about the impact of ROS induced by water limitation on bacteria performing important processes as pollutant biodegradation in the environment. We have rigorously examined the physiological consequences of the rise of intracellular ROS caused by matric stress for the toluene- and xylene-degrading soil bacterium Pseudomonas putida $\mathrm{mt}-2$.
\end{abstract}

Methods: For the current experiments, controlled matric potential stress was delivered to $P$. putida cells by addition of polyethylene glycol to liquid cultures, and ROS formation in individual cells monitored by a specific dye. The physiological response to ROS was then quantified by both RT-qPCR of RNA transcripts from genes accredited as proxies of oxidative stress and the SOS response along with cognate transcriptional GFP fusions to the promoters of the same genes.

Results: Extensive matric stress at $-1.5 \mathrm{MPa}$ clearly increased intracellular accumulation of ROS. The expression of the two major oxidative defense genes $k a t A$ and $a h p C$, as well as the hydroperoxide resistance gene osmC, was induced under matric stress. Different induction profiles of the reporters were related to the severity of the stress. To determine if matric stress lead to induction of the SOS-response, we constructed a DNA damage-inducible bioreporter based on the LexA-controlled phage promoter P PP3901. According to bioreporter analysis, this gene was expressed during extensive matric stress. Despite this DNA-damage mediated gene induction, we observed no increase in the mutation frequency as monitored by emergence of rifampicin-resistant colonies.

Conclusions: Under conditions of extensive matric stress, we observed a direct link between matric stress, ROS formation, induction of ROS-detoxifying functions and (partial) activation of the SOS system. However, such a stress-response regime did not translate into a general DNA mutagenesis status. Taken together, the data suggest that $P$. putida mt-2 can cope with this archetypal environmental stress while preserving genome stability, a quality that strengthens the status of this bacterium for biotechnological purposes.

Keywords: Pseudomonas putida mt-2, Matric stress, ROS, Oxidative stress, Bioreporters

\footnotetext{
*Correspondence: oln@plen.ku.dk

'Department of Plant and Environmental Sciences, Section of Genetics and

Microbiology, University of Copenhagen, Thorvaldsensvej 40, 1871

Frederiksberg C, Denmark

Full list of author information is available at the end of the article
} 


\section{Background}

The impact of environmental factors on the survival and activity of microorganisms involved in pollutant biodegradation is of considerable interest, as environmental stress may represent a bottleneck for their optimal performance in natural environments. Hence, previous investigations have addressed the significance of various environmental stressors (e.g., variable nitrogen sources, oxidative stressors, as well as carbon and iron starvation) on transcriptional profiles of catabolic genes in Pseudomonas putida mt-2 [1]. This toluene- and xylene-degrading soil bacterium, carrying the catabolic TOL plasmid pWW0, as well as its plasmid-cured derivative $P$. putida KT2440, are well studied paradigm organisms for applications in environmental biotechnology [2-5].

For bacterial cells residing in unsaturated habitats such as surface soils, fluctuation in water availability represents a major environmental factor affecting their survival and activity $[6,7]$. In non-saline soils capillary forces and physical sorption of water to solids, together constituting the soil matric potential, are the dominating factors determining water availability [8]. Low matric potentials (i.e., desiccation) limit transport and diffusion of nutrients, impair microbial mobility, and negatively affect the physiological activity of soil bacteria [9-11]. Importantly, desiccation may increase the endogenous formation of reactive oxygen species (ROS), and a single study has shown that P. putida micro-colonies growing on a medium containing polyethylene glycol with molecular weight of 8000 (PEG-8000), used to simulate matric stress, accumulate more ROS than the corresponding micro-colonies formed under water-replete conditions [12]. However, the physiological consequences of ROS accumulation are currently not known in detail.

In Pseudomonas and other bacteria protection against ROS and its harmful effects involves different strategies to maintain the amount of oxidants at a non-toxic level, and to repair cellular damage caused by increased levels of ROS [13, 14]. Small antioxidant molecules, for instance reduced glutathione and thioredoxin, and redirection of metabolic pathways towards routes that regenerate reducing power (e.g., NADPH) play an important role in the removal of ROS [15-18]. However, inducible enzymes, such as superoxide dismutases, catalases, and peroxidases, seem to constitute the major component of the bacterial oxidative stress defense system $[19,20]$. Surprisingly, whole genome transcriptome studies and screens for desiccation-induced genes in $P$. putida show upregulation of quite few oxidative stress responders in cells subjected to matric stress $[21,22]$. Hence, the expression of the major defense genes as katA (PP0481, catalase), ahpCF (PP2439-PP2440, alkylhydroperoxide reductase), or $\operatorname{sod} A B$ (PP0946 and PP0915, superoxide dismutase), was not induced in these studies. This might suggest that matric stress is not a very strong inducer of these oxidative stress defense genes, and that cells are either not well protected against the consequences of increased ROS levels, or use other defense mechanisms against matric stress-mediated accumulation of ROS.

If imbalances occur between the oxidant accumulation and the protective capacity of the defense system, the desiccated cells experience oxidative stress, a condition where ROS may reach levels that generate damage on the DNA [23]. DNA damage induces SOS-response dependent errorprone DNA polymerases, eventually leading to accumulation of mutations $[24,25]$. Oxidative damage to DNA is an important source of genetic variations in stressful environments [26-28]. Nevertheless, it has not been determined whether matric stress actually induces the SOS response, i.e., the LexA1 and LexA2 regulons in P. putida, and whether such an induction could result in increased genetic and phenotypic diversity of the surviving bacteria, and thereby promote adaptation to the stressful conditions bacteria encounter in unsaturated environments [12, 29].

The overall objective of this study was to obtain a comprehensive understanding of how $P$. putida mt-2 responds to increased ROS levels generated during matric stress. We carried out our experiments in a completely mixed and homogenous pure culture system, and used PEG-8000 to lower external water potential and hence simulate matric stress $[8,30]$. Our first specific aim was to determine whether major oxidative stress defense genes were differentially expressed under matric stress. Most studies on defense responses in desiccated bacterial cells rely on bulk measurements of gene expression (see for instance [21, 31]). However, in cases where a gene is not highly expressed there is a risk of masking the signal by the bulk measurement [32]. In addition, the response to environmental stimuli among individual cells of isogenic populations is often heterogeneously distributed, frequently with minor subpopulations dominating the overall population behavior [33-35]. Therefore, we developed a panel of fluorescent whole-cell bioreporters to determine oxidative defense gene expression in P. putida mt-2 at the single cell level through flow cytometry. Our final specific aim was to determine if the $P$. putida SOS-response was activated during matric stress, and if such activation resulted in increased mutations rates. For that purpose, we constructed a bioreporter based on a LexA1/LexA2-regulated phage promoter [25], and determined if matric stress altered the frequency of mutations leading to resistance towards rifampicin.

\section{Results}

Matric stress induces production of endogenous ROS

In order to simulate matric stress of $-0.5 \mathrm{MPa}$ or a more extensive matric stress of $-1.5 \mathrm{MPa}$, the so-called permanent plant wilting point (referred to as "mild" or "extensive" matric stress, respectively) we grew wildtype $P$. putida mt-2 cells in liquid media containing the non-permeating solute PEG-8000 to lower the water potential [8]. The formation of intracellular ROS was 

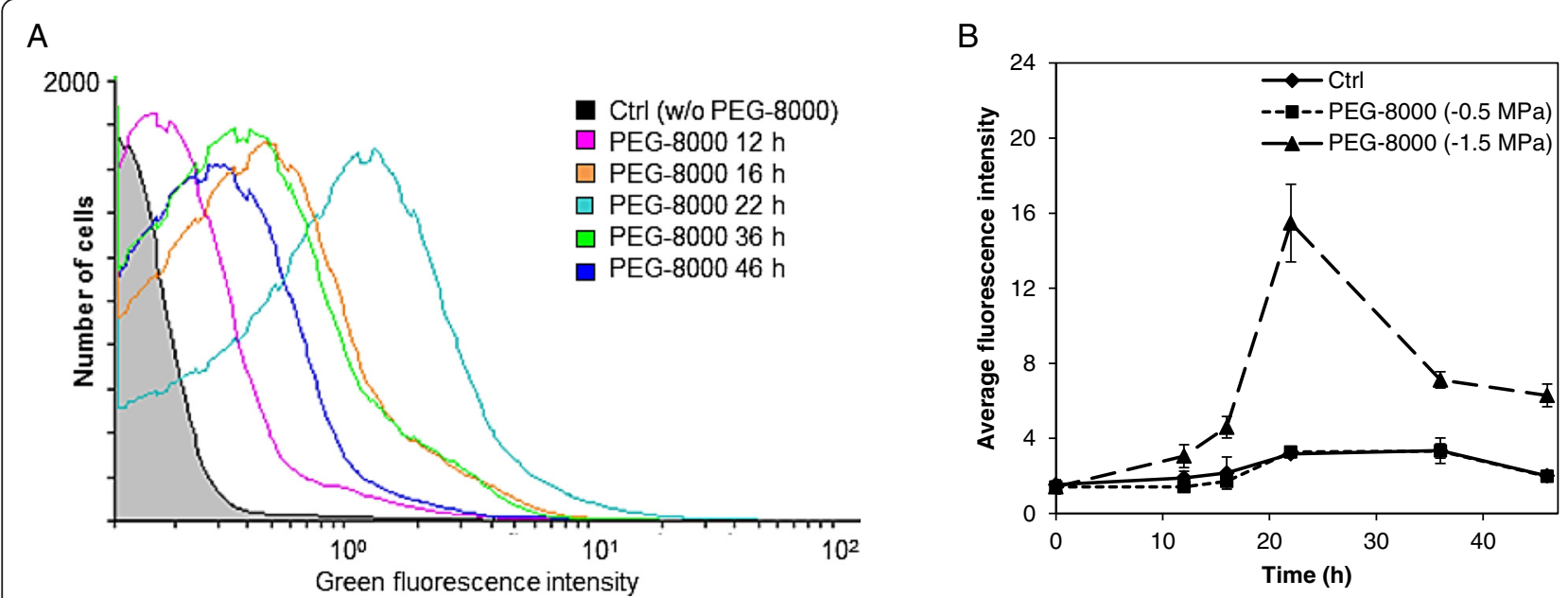

Fig. 1 Accumulation of reactive oxygen species (ROS) in P. putida mt-2 following matric stress. Matric stress was simulated by incubation in liquid culture media amended with PEG-8000 to obtain matric potentials of $-0.5 \mathrm{MPa}$ or $-1.5 \mathrm{MPa}$. ROS were detected as oxidation-dependent green fluorescence of the ROS-sensitive probe 2',7'-dichlorodihydrofluorescein diacetate. a Histogram illustrating the fluorescence from one representative experiment where cells were either incubated without PEG-8000 (considered control, Ctrl) or exposed to PEG-8000 (-1.5 MPa). b Average fluorescence intensity of cells from PEG-8000 treated cultures and Ctrl cultures. Data represent mean values \pm S.D. $(n=3)$

detected as the fluorescence arising from the ROS-sensitive green fluorescent dye $2^{\prime}, 7^{\prime}$-dichlorodihydrofluorescein diacetate $\left(\mathrm{H}_{2} \mathrm{DCF}-\mathrm{DA}\right)$ by flow cytometry. Accumulation of ROS was not detectable in cells incubated under conditions of mild matric stress (-0.5 MPa, Fig. 1). Reduction of the matric potential to $-1.5 \mathrm{MPa}$ on the other hand clearly increased the endogenous ROS formation as compared to the untreated control (Fig. 1). The response was pronounced after $>10 \mathrm{~h}$ and accumulation of ROS peaked after $22 \mathrm{~h}$ ( $\sim 15$ fold increase in ROS-dependent fluorescence compared to control cells). These results documented that cells experiencing extensive matric stress even in liquid culture accumulate ROS, and prompted us to construct a panel of bioreporters for oxidative stress responses.

\section{Construction of bioreporters for oxidative stress}

We constructed four oxidative stress responsive bioreporters based on the promoters for the major stress defense genes katA (PP0481), ahpC (PP2439), sodB (PP0915), and further included osmC (PP0089) as the expression of this gene appears to be upregulated in surface-grown $P$. putida cells exposed to matric stress imposed by suction [21]. These four bioreporters were based on the medium-copy-number plasmid vector, pSEVA237M of the SEVA collection [36]. Initially we quantified the expression of the selected genes by RT-qPCR under conditions that are known to increase the levels of intracellular ROS. In cells incubated with $1.5 \mathrm{mM}$ $\mathrm{H}_{2} \mathrm{O}_{2}$, both katA and $\operatorname{ahpC}$ were transiently upregulated after $30 \mathrm{~min}$ (Fig. 2a). A comparable or even higher expression level was observed for cells treated with the superoxide-generator, paraquat (PQ, added at $100 \mu \mathrm{M})$. Also the osm $C$ gene was significantly $(P<0.05)$, though not very highly, induced in cells treated with $\mathrm{H}_{2} \mathrm{O}_{2}$, but not with $\mathrm{PQ}$, and the response of $\operatorname{osm} C$ to oxidative stress was slower than the responses of $k a t A$ and $a h p C$. Upregulation of $\operatorname{sodB}$ was on the other hand not detectable with any of the tested oxidative stress inducers, neither after 30 min nor after $2 \mathrm{~h}$ of incubation. On the contrary, expression of $\operatorname{sodB}$ seemed to be downregulated in the stressor-treated cells.

The ability of the four plasmid-based bioreporters to respond to the oxidative stress conditions created by incubation with $1.5 \mathrm{mM} \mathrm{H}_{2} \mathrm{O}_{2}$ or $100 \mu \mathrm{M}$ PQ was tested by flow cytometry. Figure $2 \mathrm{~b}$ illustrates the average fluorescence intensity of $\mathrm{H}_{2} \mathrm{O}_{2}$ - or PQ-treated cells normalized to the average fluorescence intensity of control cells incubated without a stress inducer. In contrast to the transient upregulation of the katA and $a h p C$ after 30 min seen by RT-qPCR, the signal from the reporters having msf-gfp fused to $\mathrm{P}_{\text {katA }}$ or $\mathrm{P}_{a h p C}$ increased up to at least $8 \mathrm{~h}$ of stress exposure. The reporter based on $\mathrm{P}_{\text {osm }}$ had a weaker and later response to $\mathrm{H}_{2} \mathrm{O}_{2}$ and $\mathrm{PQ}$ than $\mathrm{P}_{\text {katA }}$ and $\mathrm{P}_{a h p C}$, which is in agreement with the profile of osm $C$ expression measured by RT-qPCR (compare Fig. 2a and b). However, in contrast to the RT-qPCR data from the PQ treatment, flow cytometry data for this treatment revealed a small, but significant $(P<0.05)$ induction of $\mathrm{P}_{\text {osm }}$, emphasizing the improved sensitivity of the reporters based on detection of fluorescence of the stable GFP protein. The reporter based on $\operatorname{sodB}$ did not respond to $\mathrm{PQ}$; however, after 5 and $8 \mathrm{~h}$ there was a minor induction of $\mathrm{P}_{\text {sodB }}$ in cells exposed to $\mathrm{H}_{2} \mathrm{O}_{2}(P<0.05)$.

\section{Matric stress activates major oxidative stress response genes}

The reporter strains were used to evaluate the physiological response to ROS accumulation under matric stress. As shown in Fig. 3, the katA, ahpC, and osmC 

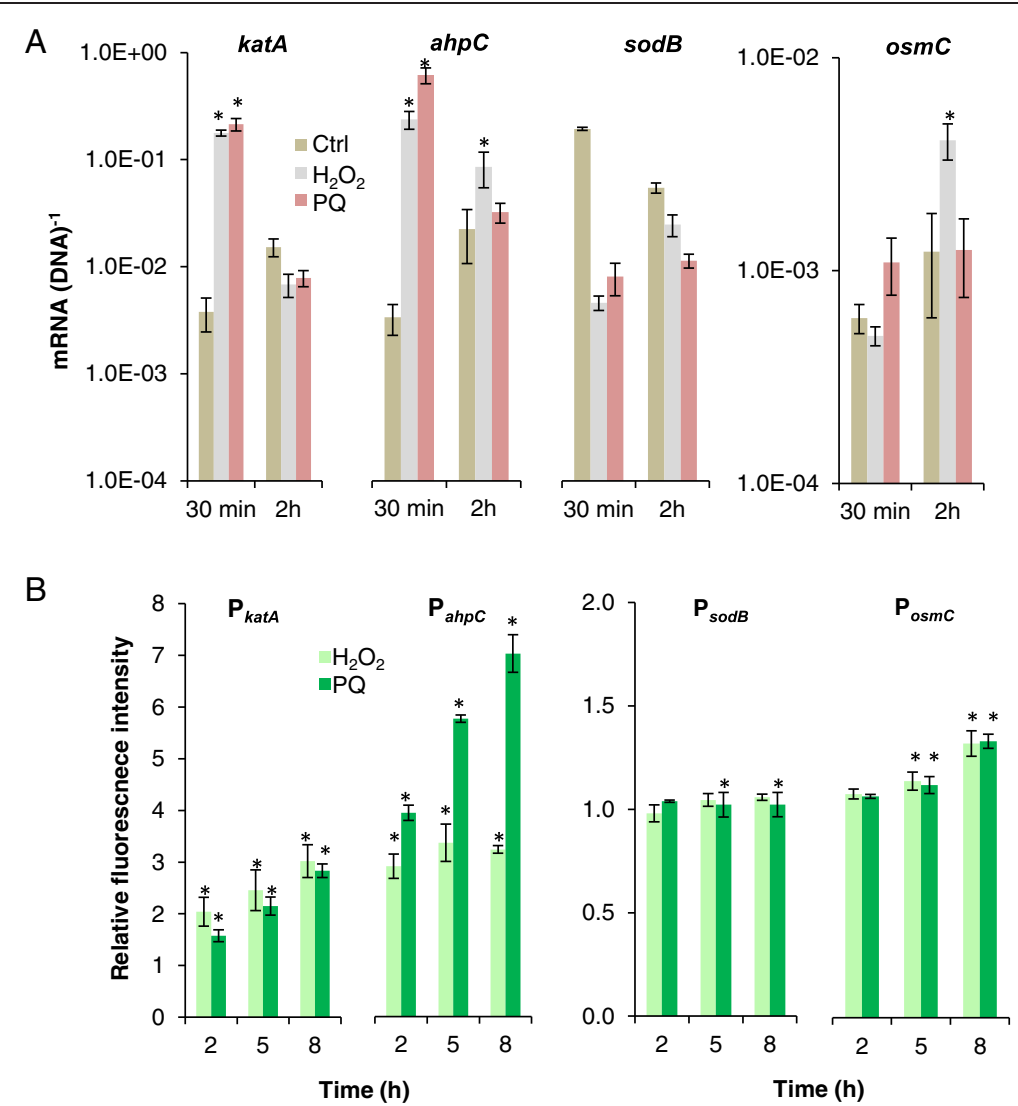

Fig. 2 Response of oxidative stress-associated genes and promoters. a Expression of katA, ahpC, sodB, and osmC from P. putida mt-2 in the presence of $\mathrm{H}_{2} \mathrm{O}_{2}(1.5 \mathrm{mM})$, paraquat $(\mathrm{PQ}, 100 \mu \mathrm{M})$, or without an oxidative stress inducer (control, Ctrl) as measured by RT-qPCR. Cells were sampled $30 \mathrm{~min}$ and $2 \mathrm{~h}$ after addition of the stress inducer. Data are mean values \pm S.D. $(n=3)$ of mRNA per DNA of the gene in question. Asterics $(*)$ indicate mean values of treated cultures that are significantly $(P<0.05)$ higher than mean values from Ctrl cultures. Note the different scale for the $y$-axis of the diagram of osmC expression. $\mathbf{b}$ Induction of pSEVA237M-based bioreporters in P. putida mt-2 cultured in the presence of $\mathrm{H}_{2} \mathrm{O}_{2}(1.5 \mathrm{mM})$ or $\mathrm{PQ}(100 \mu \mathrm{M})$ after $2-8 \mathrm{~h}$ of stress exposure. Data are mean values \pm S.D. $(n=3)$ of average fluorescence intensity of cells treated with either $\mathrm{H}_{2} \mathrm{O}_{2}$ or $\mathrm{PQ}$ normalized to the average fluorescence intensity of $\mathrm{Ctrl}$ cells. Asterisks $\left(^{*}\right)$ indicate mean values from treated cultures that are significantly $(P<0.05)$ higher than mean values from $C$ trl cultures. Note that values on the $y$-axis of the diagram of $P_{\text {kata }}$ and $P_{a h p c}$ are different from the values in the diagram of $\mathrm{P}_{\text {sodB }}$ and $\mathrm{P}_{\text {osm }}$

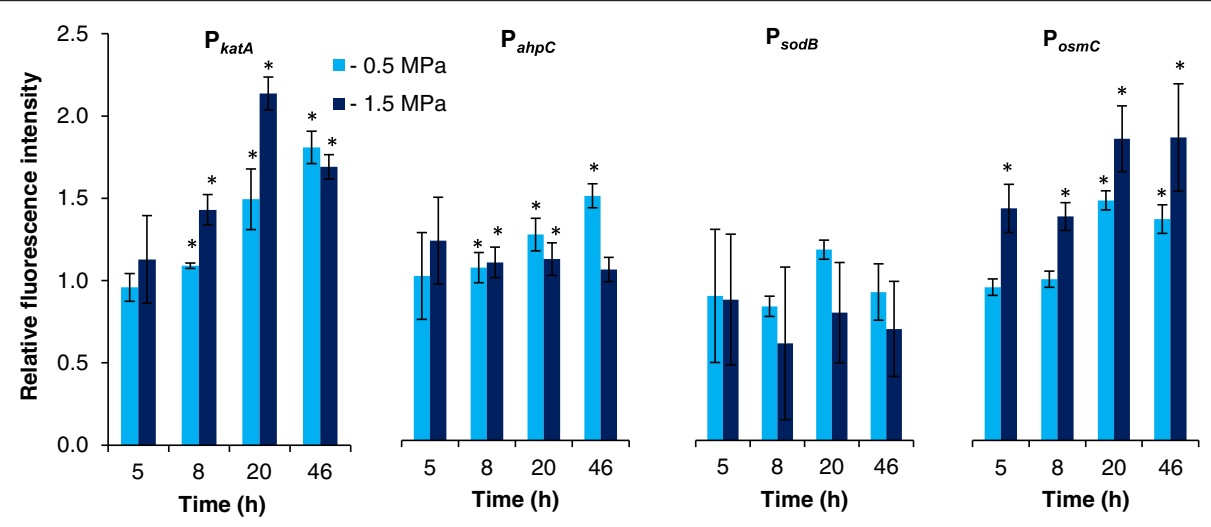

Fig. 3 Induction of pSEVA237M-based bioreporters in P. putida mt-2 under matric stress. Bioreporter cells were exposed to mild matric stress of $-0.5 \mathrm{MPa}$ or extensive matric stress of $-1.5 \mathrm{MPa}$, and fluorescence was detected by flow cytometry. Data are mean values \pm S.D. $(n=3)$ of average fluorescence intensity of cells incubated under matric stress of $-0.5 \mathrm{MPa}$ or $-1.5 \mathrm{MPa}$ normalized to the average fluorescence intensity of Ctrl cells. Asterisks $\left(^{*}\right)$ indicate mean values from treated cultures that are significantly $(P<0.05)$ higher than mean values from Ctrl cultures. 
reporters all responded to the two tested matric stress scenarios. In contrast, the $\operatorname{sod} B$ promoter was not activated by matric stress. The induction profiles of $\mathrm{P}_{\text {katA }}$, $\mathrm{P}_{a h p C}$, and $\mathrm{P}_{\text {osm }}$ differed noticeable as compared to induction profiles obtained for cells exposed to $\mathrm{H}_{2} \mathrm{O}_{2}$ or PQ (compare Figs. $2 \mathrm{~b}$ and 3 ). At the time points tested here, the katA reporter showed the best response under both matric stresses. However, even the $\mathrm{P}_{\text {osm } C}$ reporter that only showed a weak induction by $\mathrm{H}_{2} \mathrm{O}_{2}$ and PQ was induced to an extent comparable to $\mathrm{P}_{\text {kat }}$ under extensive matrix stress $(-1.5 \mathrm{MPa})$. Despite lack of detection of ROS accumulation in cells exposed to mild matric stress of $-0.5 \mathrm{MPa}$ (Fig. 1), $\mathrm{P}_{\text {katA }}, \mathrm{P}_{\text {osm }}$ and $\mathrm{P}_{a h p C}$ were induced under this stress scenario. After $46 \mathrm{~h}$ the induction of $\mathrm{P}_{a h p C}$ was even higher for cells exposed to mild matric stress compared to cells incubated under extensive matric stress $(-1.5 \mathrm{MPa})$. Hence, we could demonstrate induction of two major oxidative defense genes, as well as of $\operatorname{osmC}$, during matric stress, and relate different induction profiles of the different reporters to the severity of the stress.

\section{Matric stress induces the LexA-regulated PP3901 gene, but does not increase mutation frequency}

If intracellular levels of ROS exceed the cellular defense capacity, oxidative stress is encountered which may lead to DNA-damage and ultimately cell death. To determine if matric stress resulted in enhanced cell death, a live/dead viability staining was performed and analyzed by flow cytometry. In accordance with the lack of detection of ROS accumulation under mild matric stress, cell viability was not affected under this condition (Fig. 4). Extensive matric stress did increase the proportion of cells with injured membranes with time of incubation. As the levels of ROS were severe enough to induce an oxidative stress response in the cells, we then speculated that another consequence of these ROS could be to elicit damage to DNA that would induce the SOS-system and eventually translate into an increase of non-lethal mutations in the matric stressed cells.

A previous study by Abella and colleagues [25] indicated that the gene PP3901 from a resident prophage is required for DNA damage-mediated induction of a number of other prophages in P. putida. The PP3901 gene is member of the LexA1 as well as the LexA2 regulons; hence, we exploited the promoter of this gene for the construction of a DNA damage-inducible bioreporter. According to RT-qPCR analysis, expression of PP3901 was upregulated in the presence of $1.5 \mathrm{mM} \mathrm{H}_{2} \mathrm{O}_{2}$, while incubation with $100 \mu \mathrm{M}$ PQ did not increase the expression (Fig. 5a). Consistently, the constructed Tn7-based bioreporter carrying a chromosomal integrated $\mathrm{P}_{\mathrm{PP} 3901}-g f p$ fusion only responded to the $\mathrm{H}_{2} \mathrm{O}_{2}$-treatment, and not to PQ in the concentration tested here (Fig. 5b). The induction of the reporter by $\mathrm{H}_{2} \mathrm{O}_{2}$ was nevertheless low when compared to the induction by the DNA-damaging agent nalidixic acid (Fig. 5b).

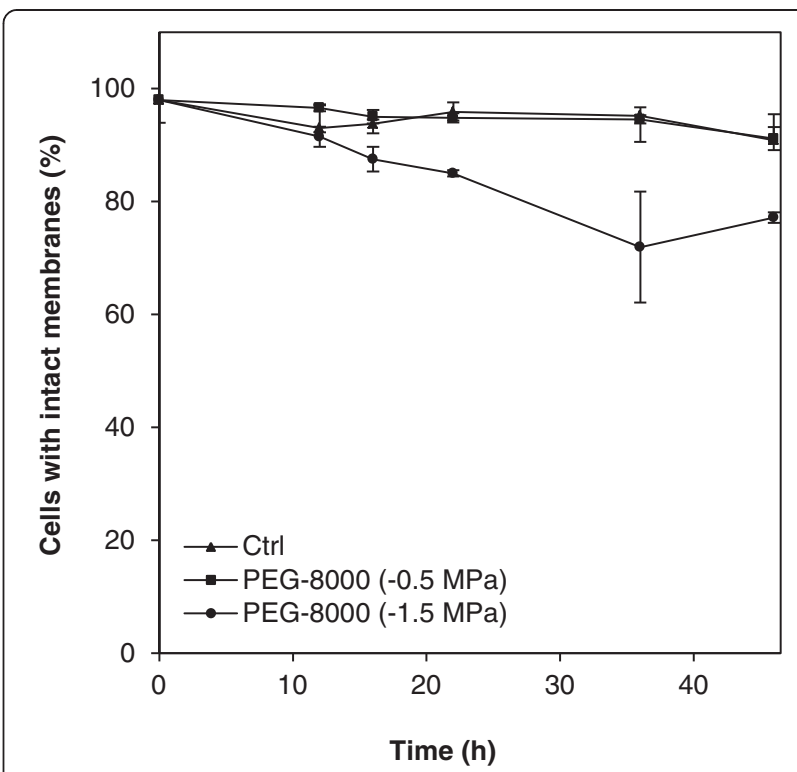

Fig. 4 Viability of P. putida mt-2 cells exposed to matric stress. The viability, following incubation without matric stress (control, Ctrl), under mild matric stress $(-0.5 \mathrm{MPa})$, or under extensive matric stress $(-1.5 \mathrm{MPa})$, was determined by live/dead staining and flow cytometry. Data are mean values and error bars represent the standard deviation of three biological replicate samples

Subsequently, we analyzed the response of the bioreporter when cells were exposed to matric stress. Mild matric stress did not have any impact, whereas the extensive matric stress resulted in weak, though significant $(P<0.05)$ induction of the bioreporter (Fig. 6a). Despite this DNA-damage mediated gene induction, the extensive matric stress did not increase the mutation frequency as measured by the standard assay of appearance of colonies having resistance to rifampicin $\left(\mathrm{Rif}^{\mathrm{R}}\right)$ from cultures incubated under the stress condition (Fig. 6b).

\section{Discussion}

In the current study we address the impact of desiccation, which is considered to be a major stressor in soil environments, on the soil bacterium P. putida mt-2 that is widely used as a model organism for studies in environmental microbiology and biotechnology. In particular, we focus on the ability of matric stress to increase intracellular ROS levels and on the physiological responses that $P$. putida launches in response to this stressor.

We have shown that $P$. putida $\mathrm{mt}-2$ cells in liquid cultures accumulate ROS when they are subjected to matric stress simulated by addition of the non-permeating solute PEG8000 to the culture media. For comparison, Chang and coworkers [12] studied the accumulation of ROS in microcolony forming cells exposed to a wider range of matric potentials. They showed that ROS accumulation was taking place at water potentials below $-0.5 \mathrm{MPa}$; conditions where cells respond to desiccation by altering the composition of 
A

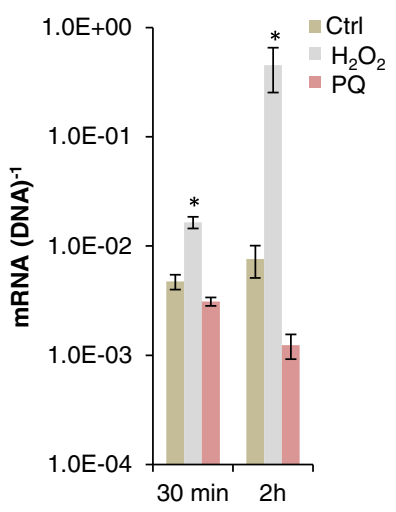

B

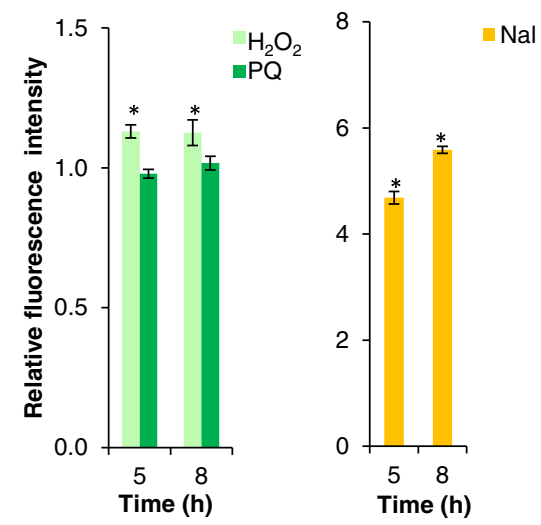

Fig. 5 Verification of expression of gene PP3901 induced by oxidative stress conditions. a Expression of PP3901 in the presence of $\mathrm{H}_{2} \mathrm{O}_{2}(1.5 \mathrm{mM})$, paraquat $(P Q, 100 \mu M)$, or without an oxidative stress inducer (control, Ctrl) quantified by RT-qPCR.Data are mean values \pm S.D. $(n=3)$ of mRNA per DNA of the gene in question. Asterics $\left(^{*}\right)$ indicate mean values of treated cultures that are significantly $(P<0.05)$ higher than mean values from Ctrl cultures. $\mathbf{b}$ Induction of the bioreporter harboring a transcriptional fusion between PP3901 and msf-gfp in P. putida mt-2 after exposure $1.5 \mathrm{mM} \mathrm{H}_{2} \mathrm{O}_{2}, 100 \mu \mathrm{M}$ PQ (left panel), or $30 \mathrm{mg} \mathrm{mL}^{-1}$ nalidixc acid (right panel). Note the different scales on the $y$-axis of the diagrams. Data are mean values of average fluorescence intensity from triplicate cultures \pm S.D. Asterisks $\left.{ }^{*}\right)$ indicate mean values from treated cultures that are significantly $(P<0.05)$ higher than mean values from Ctrl cultures

their membrane fatty acids and increase production of the matrix of extracellular polymeric substance, and where physiological constraints affect their activity [11, 21, 37, 38]. The temporal dynamics of ROS accumulation observed by Chang and coworkers [12] differed slightly from our observations. For a matric potential of $-1.5 \mathrm{MPa}$, accumulation of ROS in the surface-grown cells increased slowly to peak after $3 \mathrm{~d}$ in their study. The earlier response in our liquid cultures is likely attributable to the different experimental set-up.

Increased oxidative stress under desiccation has been described in other bacterial species, and also in yeast, plant, and animal cells [39-41], however the mechanisms behind are unclear. Studies on mitochondria from Zea mays L. demonstrate that desiccation increases respiration rates which in turn increases radical formation [40]. Membrane and protein perturbations caused by matric stress (e.g., by PEG-8000 exposure) are likely to impair electron flow leading to increased ROS formation [38, 40, 42]. However, also $\mathrm{Fe}^{2+}$ autoxidation induced by membrane lipids in response to desiccation has been suggested as a source of ROS [43].

The most severe consequence of oxidative stress is cell death, which can be caused by lethal damage of proteins, components of the lipid membrane, and nucleic acids [19, 44, 45]. Viability staining of cells subjected to matric stress indicated that mortality was not a major consequence of the increased ROS levels in our study. This was not surprising
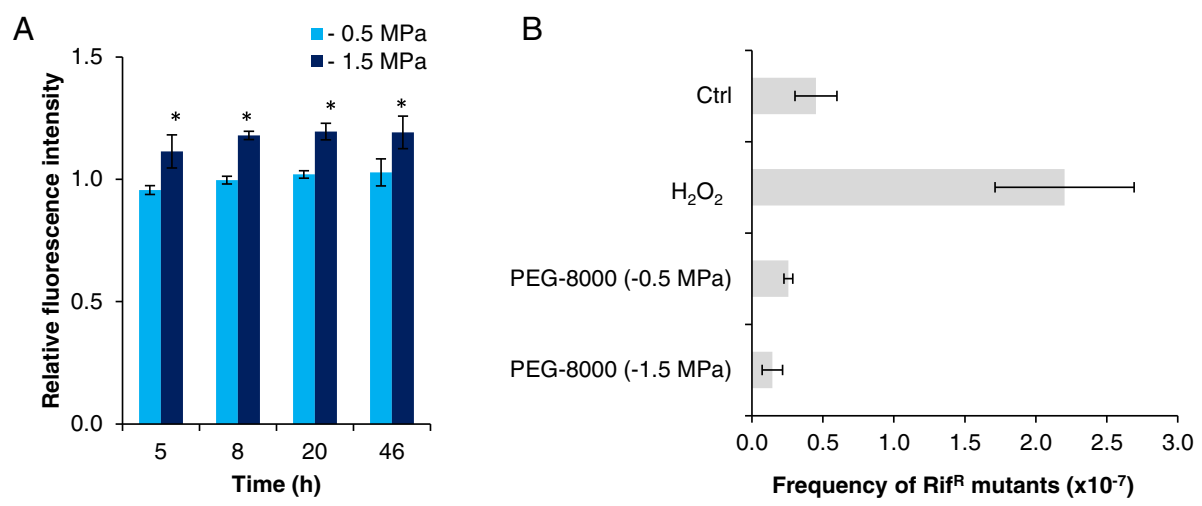

Fig. 6 Induction of the DNA-damage inducible PPP3901 bioreporter and frequency of mutations conferring rifampicin resistance in P. putida mt-2 following ex-

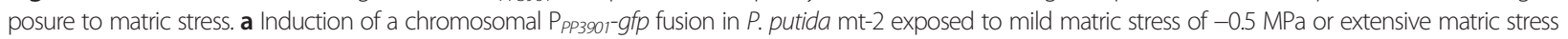
of $-1.5 \mathrm{MPa} 5-46 \mathrm{~h}$ post stress induction. Data represent average fluorescence intensity from cells exposed to matric stress normalized to average fluorescence intensity from control cells.b Occurrence of clones conferring resistance to rifampicin (100 $\mathrm{gg} \mathrm{mL}^{-1}$ ) normalized to the number of CFU on LB agar without rifampicin following a 72-h incubation with either $\mathrm{H}_{2} \mathrm{O}_{2}$, matric stress $(-0.5 \mathrm{MPa}$ or $-1.5 \mathrm{MPa}$ ), or without any stress inducer (control, Ctrl). Data are mean values \pm S.D. $(n=3)$. Asterisks $\left(^{*}\right)$ indicate mean values from treated cultures that are significantly $(P<0.05)$ higher than mean values from Ctrl cultures 
for cells incubated under $-0.5 \mathrm{MPa}$ since accumulation of ROS was not detectable in our system. However, even for cells exposed to extensive matric stress for $46 \mathrm{~h}$ the reduction in viability compared to untreated cells was $<15 \%$. Hence, it is reasonable to state that the cells were subjected to sublethal stress conditions.

We could demonstrate induction of major oxidation stress defense genes by $P$. putida $\mathrm{mt}-2$ under both mild and extensive matric stress. Consequently, the current study adds new knowledge on the physiological responses to accumulation of ROS as a consequence of desiccation. We took advantage of employing a panel of stable GFPbioreporters based on promoters for genes previously reported to be involved in the response to oxidative stress $[20,46]$. The reporters collect the prehistory of promoter activity up till the sampling point, and therefore enable detection of small differences in expression of a fast responding gene. Hereby we were able to detect induction of $k a t A$ and $a h p C$, and also of $o s m C$, which is putatively involved in hydroperoxide resistance. Superoxide radicals are eliminated by superoxide dismutase, and significant induction of the corresponding genes has been found in diverse bacterial species following desiccation [31, 41]. However, $\operatorname{sod} B$ did not appear to be involved in protection against matric stress-derived ROS in P. putida mt-2.

Application of the bioreporter panel provides a broad coverage of different oxidative stressors and stress levels. Catalase and alkylhydroperoxide reductase, encoded by kat $A$ and $a h p C F$, respectively, are both regulated by OxyR. Both functions are known to act as primary scavengers of $\mathrm{H}_{2} \mathrm{O}_{2}$ in Escherichia coli and, based on data from this work, they likely play a similar role in $P$. putida $[13,47]$. The $\mathrm{P}_{\text {katA }}$ construct had a higher response than $\mathrm{P}_{a h p C}$ towards accumulation of endogenous ROS detected with the fluorescent ROS-responsive probe $\mathrm{H}_{2}$ DCF-DA; in particular when facing increased ROS accumulation under extensive matric stress. In accordance, catalases are reported to function better with higher peroxide concentrations [13]. AhpCF functions as a peroxidase that is dependent on NADH to restore its activity, and hence is not effective in removing large amounts of peroxides [48]. This could explain the poorer induction of the $a h p C$ reporter under extensive matric stress $(-1.5 \mathrm{MPa})$ than under mild matric stress $(-0.5 \mathrm{MPa})$ after $46 \mathrm{~h}$.

The $\operatorname{osm} C$ gene encodes an enzyme, which in E. coli is referred to as a hydroperoxide resistance protein involved in defense against organic hydroperoxides in particular $[15,49]$. In Pseudomonas aeruginosa, osm $C$ is induced by ethanol and osmotic stress, but not by peroxides, and an osm $C$ mutant does not show impaired survival under oxidative stress [50]. In P. putida, the exact function of OsmC has not yet been addressed. The current study shows that $\mathrm{P}_{\text {osm } \mathrm{C}}$ responds poorly to $\mathrm{H}_{2} \mathrm{O}_{2}$, but the promoter is clearly induced by matric stress. These results suggest that OsmC in P. putida mt-2 could be involved in a more general protection against desiccation damage, rather than specifically in defense against the associated production of ROS. Nevertheless, induction of osmC, in conjunction with the induction of major oxidative stress defense genes as $\mathrm{katA}$ and/or $a h p C$, may still be a useful indicator of matric stressed cells challenged by increased ROS levels. In a study by Gülez and coworkers [21], the expression of osmC (but none of the classical oxidative stress defense genes) was upregulated in the transcriptome analyzed after 4,24 , and $48 \mathrm{~h}$ when $P$. putida KT2440 was challenged with mild matric stress $(-0.4 \mathrm{MPa})$. As the level of mRNA shows rapid temporal dynamics it is possible that expression of these genes were missed in the study by Gülez and coworkers. It should however be noted that these authors used a porous surface model system to impose matric stress as opposed to the PEG-8000 simulated stress employed in the current study and these two stress scenarios appear to lead to expression of slightly different genes [21].

At sublethal levels of ROS accumulation, as those experienced by $P$. putida $\mathrm{mt}-2$ in the current study, oxidative stress-induced DNA damage plays a role in generating adaptive mutations, conferring fitness advantages to cells in challenging environments [26, 51,52]. Desiccation is reported to induce DNA repair mechanisms such as the MutT system [21, 31, 53], but in P. putida mt-2 it remains unknown whether the SOS system, and its error-prone DNA polymerases is activated during matric stress.

Under extensive matric stress we detected induction of the bioreporter harboring the promoter of a resident prophage gene, PP3901. Prophage-induction is a known stress-response in $P$. putida and other bacteria mediated by the SOS system [39, 54-56]. In P. putida KT2440, the SOS regulon includes two LexA proteins, and only the gene PP3901, which is required for DNA damagemediated induction of several other prophage genes, is under control of both proteins [25]. This gene has not been used as an indicator of DNA damage before, but its expression was previously found to be upregulated in mitomycin C-treated cells [25]. As the promoter clearly was induced by DNA-damage introduced by exposure to nalidixic acid, our result indicates that the DNA-damage mediated SOS-response was indeed activated, albeit not very highly, in matric stressed cells. This DNA damage did not translate into a detectably increase in mutation frequency in the genome of $P$. putida $\mathrm{mt}-2$ when exposed to extensive matric stress. Thus we can conclude that neither oxygen radicals themselves, nor error-prone DNA damage repair mechanisms introduced mutations to the desiccated cells despite the high ROS levels detected. Our study therefore provides indications that desiccation stress experienced at matric potentials down to $-1.5 \mathrm{MPa}$, i.e., the permanent wilting point of plants, ensuing production 
of ROS and the subsequent moderate induction of the SOS system can be managed by $P$. putida $\mathrm{mt}-2$ without starting a genetic diversification regime. In this respect, it is often ignored that induction of stress defenses does not necessarily signifies that a cell per se is stressed. In contrast, induction of the defense may provide the cell with tolerance towards the stressor in question. Oxidative stress is only encountered when the level of radicals exceed the capacity of the cell's defense system to detoxify the oxidants [23]. The concomitant analysis of ROS accumulation, oxidative defense gene expression, viability and response to DNA damage, which is carried out in the current study permit us to make indications of the stress level of desiccated cells. Under mild matric stress, early induction of the defense system of $P$. putida $\mathrm{mt}-2$ seems to be able to eliminate ROS at the same rate as it is produced, at least in the initial part of the experiment. This is supported by the high viability of these cells. Hence these cells cannot be categorized as stressed, although, in the long term the defense might be overwhelmed resulting in ROS accumulation, as we started to observe after $46 \mathrm{~h}$. Contrary, for cells under extensive matric stress, we speculate that ROS formation exceeds the capacity of the defense system already within $12 \mathrm{~h}$ with a resulting slight decrease in viability. Nevertheless, the stress was not translated into higher mutation frequencies.

The stress model adopted in the current study captures essential features of the life conditions for $P$. putida mt-2 residing in a drying soil as we used the non-permeating solute PEG-8000 to simulate matric stress to cells in liquid culture. However, it does not reflect in its entirety all constraints to the bacterial cells that they would encounter in a drying soil. For instance, the thin water films on soil surfaces in unsaturated pore spaces reduce the substrate and nutrient availability. Thus, less energy may be available for production of antioxidants, and secondly carbon starvation, which occurs in soil [57], is known to induce mutagenesis through an RpoS-mediated response [10, 11, 20, 58]. In this respect, the panel of hereby described bioreporters will be valuable for examining the manifestation of traits detected in the test tube in a more complex conditions, whether in soil or in the distinct environment of a biotechnological setup.

\section{Conclusion}

Combining in vivo detection of endogenous ROS with viability staining and induction-profiling of genes involved in the oxidative stress response revealed that $P$. putida $\mathrm{mt}-2$ is able to restrict major cellular damages from matric stress-induced accumulation of ROS. This is done by inducing the oxidative stress defense system, including both a catalase and peroxidases. Under conditions of mild matric stress, the defense system seems to be able to remove excess ROS, however under extensive matric stress conditions ROS is built up over time. This had nevertheless only a minor impact on total population viability, and despite a slight induction of the SOS response, the accumulation of ROS did not result in increased mutation frequencies in this system. Future work conducted under more realistic conditions in desiccated soil is now needed to determine if these responses can be generalized for bacteria in the environment. The developed panel of bioreporters will also in these more natural systems be a valuable tool.

\section{Methods}

\section{Bacterial strains and growth conditions}

Wild-type strain Pseudomonas putida mt-2, obtained from Deutsche Sammlung von Mikroorganismen und Zellkulturen GmbH (DSMZ, DSM-6125), and P. putida $\mathrm{mt}-2$ strains carrying plasmid-borne msfGFP-reporter constructs, as well as strains with chromosomal insertions of mini-Tn7 transposon harboring msfGFP-reporter cassettes were used throughout this study. All strains of $P$. putida mt-2 were cultured in M9 minimal medium $(6 \mathrm{~g} / \mathrm{L}$ $\mathrm{Na}_{2} \mathrm{HPO}_{4}, 3 \mathrm{~g} / \mathrm{L} \mathrm{KH}_{2} \mathrm{PO}_{4}, 0.5 \mathrm{~g} / \mathrm{L} \mathrm{NaCl}, 1 \mathrm{~g} / \mathrm{L} \mathrm{NH} \mathrm{NH}_{4} \mathrm{Cl}$, $0.13 \mathrm{~g} / \mathrm{L} \mathrm{MgSO}_{4}$, and $0.01 \mathrm{~g} / \mathrm{L} \mathrm{CaCl}_{2}$ ) containing $10 \mathrm{mM}$ sodium succinate at $28{ }^{\circ} \mathrm{C}$ with agitation at 150 r.p.m. For standard cloning and plasmid propagation, Escherichia coli CC118 $\lambda$ pir and DH5 $\alpha$ were used. E. coli strains were cultured in Luria-Bertani broth (LB) $(10 \mathrm{~g} / \mathrm{L}$ tryptone, $5 \mathrm{~g} / \mathrm{L}$ yeast extract, and $10 \mathrm{~g} / \mathrm{L} \mathrm{NaCl}$ ) at $37{ }^{\circ} \mathrm{C}$ and agitation at 150 r.p.m., or grown on solid LB medium containing $15 \mathrm{~g} / \mathrm{L}$ agar. When needed, antibiotics were applied to the solid or liquid culture media $(10 \mu \mathrm{g} / \mathrm{mL}$ gentamycin or $50 \mu \mathrm{g} / \mathrm{mL}$ kanamycin).

All experiments with $P$. putida mt-2 were conducted as follows. Overnight cultures were pelleted by centrifugation $\left(5000 \times g\right.$ for $\left.10 \mathrm{~min}, 2{ }^{\circ} \mathrm{C}\right)$, and cells were resuspended and diluted in fresh medium to obtain an optical density at $600 \mathrm{~nm}\left(\mathrm{OD}_{600}\right)$ of 0.2 . In experiments with chemical stress-induction by $\mathrm{H}_{2} \mathrm{O}_{2}$, PQ or nalidixic acid, cultures were incubated for $2.5 \mathrm{~h}$ before addition of one of the stressors to final concentrations of $1.5 \mathrm{mM} \mathrm{H}_{2} \mathrm{O}_{2}, 100 \mu \mathrm{M} \mathrm{PQ}$, or $30 \mu \mathrm{g} / \mathrm{mL}$ nalidixic acid. Untreated cultures served as controls in all experiments. In experiments with simulation of desiccation by addition of polyethylene glycol (molecular weight = 8000; PEG-8000), the cultures were incubated for $2.5 \mathrm{~h}$ and then pelleted by centrifugation as described above before resuspending the cells in M9 medium containing either $150 \mathrm{~g} / \mathrm{L}$ or $330 \mathrm{~g} / \mathrm{L}$ PEG-8000 to obtain matric potentials of $-0.5 \mathrm{MPa}$ or $-1.5 \mathrm{MPa}$, respectively [8].

\section{Quantification of expression of genes involved in oxidative stress defense by RT-qPCR}

Wild-type $\mathrm{mt}-2$ cells were incubated in the presence of oxidative stress generators $\left(\mathrm{H}_{2} \mathrm{O}_{2}\right.$ and $\left.\mathrm{PQ}\right)$, DNA-damage 
generator (nalidixic acid) or without a stressor as described above. After $30 \mathrm{~min}$ and $2 \mathrm{~h}$ of incubation, $100 \mu \mathrm{L}$ samples were collected, immediately flash frozen in liquid nitrogen and stored at $-70{ }^{\circ} \mathrm{C}$. Before nucleic acid extraction, samples were treated with lysozyme $(100 \mu \mathrm{L}$ of $1 \mathrm{mg} / \mathrm{mL}$ in $10 \mathrm{mM}$ Tris $\cdot \mathrm{HCl}$ buffer, $\mathrm{pH} 8$, per sample of $100 \mu \mathrm{L}$ ) for $20 \mathrm{~min}$ at room temperature. DNA and RNA were co-extracted with the AllPrep DNA/RNA extraction kit (QIAGEN, UK) according to the manufacturer's protocol. Prior to reverse transcription of RNA, genomic DNA was eliminated from the RNA samples with RQ1 RNasefree DNase 1 (Promega, USA) according to the manufacturer's protocol. cDNA was synthesized immediately thereafter by using the Omniscript RT Kit (QIAGEN) including random hexamer primers (Promega) and SUPER RNase inhibitor (Ambion, USA) as previously described [59]. DNase-treated control reactions were prepared in parallel for RNA samples without addition of reverse transcriptase to ensure the absence of genomic DNA contamination.

Expression of the genes katA (PP0481), ahpC (PP2439), sodB (PP0915), osmC (PP0089), and the prophage gene PP3901 was quantified by qPCR using the Stratagene Brilliant III SYBR Green QPCR Master Mix (Agilent Technologies, USA). The primers used for amplification were the following: katA-Fw (5'-CTTGAAG ACCGAAATGGAG-3') and katA-Rv (5'-GTTTGTTTAC CGACCTCTTC-3') [46] for katA, ahpC-Fw (5'-GCG TGGAAATCTACGGTGTT- $3^{\prime}$ ) and ahpC-Rv (5'-CTT CGCCTTCTTTCCACTTG-3') for $a h p C$, sodB-Fw (5' -A GGGAACCGTCAGCTTTCTT-3') and sodB-Rv (5'-GC ACCACAACACCTATGTCG-3') for $\operatorname{sodB}$, osmC-Fw (5'-GCCTGAAGGATGGAAAAGGT-3') and osmC-Rv (5'-AAAACCGTCAGCTTGCTTGT-3') for osmC, and PP3901-Fw (5'-CACATCCTTCGACCTCCTTG-3') and PP3901-Rv (5'-TTTTCCCAGGTCACACGAAC-3') for the PP3901 gene. A standard curve was prepared as a tenfold serial dilution of DNA extracted from a stationary phase culture of P. putida $\mathrm{mt}-2$. Gene expression was calculated as mRNA transcripts of each gene, determined from the numbers of cDNA copies, normalized to the DNA copy number of the corresponding gene.

\section{Construction of GFP-based bioreporters}

The oxidative stress-responsive bioreporters were constructed by inserting the promoter regions of $k a t A$, $a h p C$, $\operatorname{sodB}$, and osmC into EcoRI/BamHI sites of the pBBR1-based broad-range-host vector pSEVA237M harboring a promoterless monomeric superfolder $g f p$ gene [36]. The DNA-damage-inducible bioreporter was constructed by inserting the promoter region of the PP3901 gene into EcoRI/BamHI sites placed upstream a promoterless superfolder $g f p$ gene [60] of a
mini-Tn7-based delivery vector (Víctor de Lorenzo lab collection).

Fragments including the promoter regions of the genes were amplified by PCR with the following primers (restriction enzyme recognition sites are shown in italics): katA-EcoRI-Fw (5'-CGATGAATTCGGAAGACA GCGTTGCTAACC-3') and katA-BamHI-Rv (5'-CGAT GGATCCTCCATTTCGGTCTTCAAGG-3') for the region -391 to -7 upstream of katA, ahpC-EcoRI-Fw (5'-C GATGAATTCGAGCCCCTCCTCCTTGAAT-3') and ahpC-BamHI-Rv (5'-CGATGGATCCTCATGGGGTT GGAATCAGTT-3') for the region -321 to -14 upstream of $a h p C$, osmC-EcoRI-Fw (5'-CGATGAATTC GCCACCCAGAAGCGGTTA-3') and osmC-BamHI$\operatorname{Rv}$ (5'-CGATGGATCCGATGCCTCCTGGTCACTG-3') for the region -295 to -1 upstream of $o s m C$, and PP3901-EcoRI-Fw (5' -CGTAGAATTCGGCTCCTTAC CTGCGACTAA-3') and PP3901-BamHI-Rv (5'-CGTA GGATCCGGTGGTAGCGCTCCATTTAC-3') for the region -146 to -1 upstream of PP3901. Standard molecular cloning procedures were used to construct the pSEVA237M-based reporter plasmids or the mini-Tn7 vector. The correct orientation and sequence of the promoters were verified with PCR and sequencing of a $1-\mathrm{kb}$ region including the corresponding promoter and part of the msf- $g f p$ gene. Reporter and mini-Tn7 plasmids were introduced by electroporation into $E$. coli DH5 $\alpha$ or CC118גpir, respectively, and then into wildtype $P$. putida $\mathrm{mt}-2$. The plasmid pUX-BF13, providing the transposase genes, was used for chromosomal Tn7 integration [61]. Finally, the correct placement and orientation of the $\operatorname{Tn} 7$ insertion was verified by PCR as described previously [62].

\section{Detection of bioreporter responses, intracellular ROS, and cell viability by flow cytometry}

Flow cytometry analysis was performed using a BD FACSCalibur flow cytometer (Becton Dickinson, CA) equipped with an argon-ion laser of $15 \mathrm{~mW}$ with excitation at $488 \mathrm{~nm}$. To detect induction of bioreporters under the tested conditions, cells were first gated in a side scatter (SSC) vs. forward scatter (FSC) plot, and then fluorescence from GFP was recorded in the FL 1 channel (515-545 nm). For fluorescence detection culture samples of $0.5 \mathrm{ml}$ were pelleted by centrifugation $\left(7000 \times g, 5 \mathrm{~min}, 2{ }^{\circ} \mathrm{C}\right)$ and re-suspended in sterile-filtered $0.9 \%(\mathrm{w} / \mathrm{v}) \mathrm{NaCl}$ to obtain a similar optical density at $600 \mathrm{~nm}\left(\mathrm{OD}_{600}\right)$.

Detection of cells accumulating intracellular ROS after exposure to PEG-8000 was carried out using the ROSsensitive green fluorescent dye $2^{\prime}, 7^{\prime}$-dichlorodihydrofluorescein diacetate $\left(\mathrm{H}_{2}\right.$ DCF-DA [Sigma-Aldrich Co.]). Cells incubated with $1.5 \mathrm{mM} \mathrm{H}_{2} \mathrm{O}_{2}$ were included as a positive control (data not shown). For each $\mathrm{mL}$ of cells 
re-suspended in $0.9 \%(\mathrm{w} / \mathrm{v}) \mathrm{NaCl}, 20 \mu \mathrm{L}$ of $1 \mathrm{mg} / \mathrm{mL}$ solution of $\mathrm{H}_{2}$ DCF-DA in DMSO was added and the samples were incubated in the dark for $30 \mathrm{~min}$ at room temperature. Green fluorescence emission from ROSdependent oxidation of $\mathrm{H}_{2}$ DCF-DA was detected with the FL1 detector after gating the cells in a SSC vs. FSC plot.

Viability of cells following exposure to PEG-8000induced matric stress was determined by flow cytometry essentially as described by DeRoy et al. [63]. Cells were incubated in the dark with $10 \mu \mathrm{L} / \mathrm{mL}$ EDTA $(500 \mathrm{mM}, \mathrm{pH}$ 8) and $10 \mu \mathrm{L} / \mathrm{mL}$ staining solution ( $400 \mu \mathrm{M}$ propidium iodide in DMSO from the BacLight Kit [Invitrogen], and 100× SYBR Green I in DMSO [Invitrogen]) for $30 \mathrm{~min}$. Cells with compromised membranes were distinguished from cells with intact membranes in a plot of green fluorescence from SYBR Green collected by the FL1 detector vs. red fluorescence collected by the FL3 detector $(675-715 \mathrm{~nm})$.

Data from at least 50,000 cells were collected from each sample and analyzed in the software Cyflogic ${ }^{\mathrm{Tm}}$ 1.2.1 (CyFlo Ltd.) for all flow cytometry experiments.

\section{Frequency of rifampicin resistance mutations}

After $72 \mathrm{~h}$ of incubation in the presence of PEG-8000 $(150 \mathrm{~g} / \mathrm{L}$ and $330 \mathrm{~g} / \mathrm{L}), \mathrm{H}_{2} \mathrm{O}_{2}(1.5 \mathrm{mM})$, or without any stressor, cultures were pelleted by centrifugation $(5000 \times g$, $10 \mathrm{~min}, 21^{\circ} \mathrm{C}$ ), and cells were resuspended in $0.9 \%(\mathrm{w} / \mathrm{v})$ $\mathrm{NaCl}$. From each triplicate culture, $100 \mu \mathrm{L}$ of the cell suspension were spread in duplicate on LB agar plates containing $100 \mu \mathrm{g} / \mathrm{mL}$ rifampicin. For each harvested culture, six $10-\mu \mathrm{L}$ droplets of $10^{-5}$ and $10^{-6}$ dilutions in $0.9 \%(\mathrm{w} / \mathrm{v}) \mathrm{NaCl}$ were spotted on LB plates. The number of Rif $^{\mathrm{R}}$ colonies was counted after $48 \mathrm{~h}$ of incubation at $28{ }^{\circ} \mathrm{C}$ and normalized to the number of colonies on LB control plates giving the Rif-mutation frequency per CFU for each condition tested.

\section{Statistical analysis}

Mean values of two data sets were compared with the Student's $t$-test with $P<0.05$ as the cut-off value for statistical significance. All experiments were comprised of three biological replicates and carried out at least twice.

\section{Abbreviations \\ $\mathrm{H}_{2}$ DCF-DA: 2',7'-dichlorodihydrofluorescein diacetate; PEG-8000: Polyethylene glycol with molecular weight 8000; PQ: Paraquat; ROS: Reactive oxygen species.}

\section{Competing interests}

None of the authors have any competing interests.

\section{Authors' contributions}

NBS conceived the study, carried out the experimental work, analyzed the data, and drafted the manuscript. DPP participated in the construction of bioreporters and PIN helped with the design and execution of the flow cytometry-based ROS detection methodology. MHN, VDL, and ON conceived the study and helped to draft the manuscript. All authors read and approved the final manuscript.

\section{Acknowledgements}

The study was supported by the Villum Kann Rasmussen Foundation through the Center for Environmental and Agricultural Microbiology (CREAM), and the ST-FLOW, ARISYS and CONTIBUGS Projects of the 7th

Framework Program of the EC to Víctor de Lorenzo

\section{Author details}

'Department of Plant and Environmental Sciences, Section of Genetics and Microbiology, University of Copenhagen, Thorvaldsensvej 40, 1871

Frederiksberg C, Denmark. ${ }^{2}$ Systems and Synthetic Biology Program, Centro Nacional de Biotecnología (CNB-CSIC), C/ Darwin 3, 28049 Madrid, Spain.

Received: 17 April 2015 Accepted: 2 October 2015

Published online: 06 October 2015

\section{References}

1. Velázquez F, de Lorenzo V, Valls $M$. The $m$-xylene biodegradation capacity of Pseudomonas putida mt-2 is submitted to adaptation to abiotic stresses: Evidence from expression profiling of $x y l$ genes. Environ Microbiol. 2006:8:591-602.

2. Bagdasarian M, Lurz R, Riickert B, Bagdasarian MM, Frey J, Timmis KN. Specific-purpose plasmid cloning vectors II. Broad host range, high copy number, RSF1010-derived gene cloning in Pseudomonas. Gene. $1981 ; 16: 237-47$

3. de Lorenzo V, Pieper D, Ramos JL. From the test tube to the environment and back. Environ Microbiol. 2013;15:6-11.

4. Regenhardt D, Heuer H, Heim S, Fernandez DU, Strömpl C, Moore ERB, et al. Pedigree and taxonomic credentials of Pseudomonas putida strain KT2440. Environ Microbiol. 2002:4:912-5.

5. Williams PA, Murray K. Metabolism of benzoate and the methylbenzoates by Pseudomonas putida (arvilla) mt-2: evidence for the existence of a TOL plasmid. J Bacteriol. 1974;120:416-23.

6. Holden PA, Fierer N. Microbial processes in the vadose zone. Vadose Zone J. 2005;:1-21.

7. Holden PA, Halverson LJ, Firestone MK. Water stress effects on toluene biodegradation by Pseudomonas putida. Biodegradation. 1997;8:143-51.

8. Holden PA. Biofilms in unsaturated environments. Methods Enzymol. 2001;337:125-43.

9. Dechesne A, Or D, Gülez G, Smets BF. The porous surface model, a novel experimental system for online quantitative observation of microbial processes under unsaturated conditions. Appl Environ Microbiol. 2008;74:5195-200.

10. Or D, Smets BF, Wraith JM, Dechesne A, Friedman SP. Physical constraints affecting bacterial habitats and activity in unsaturated porous media a review. Adv Water Resour. 2007;30:1505-27.

11. Stark JM, Firestone MK. Mechanisms for soil moisture effects on activity of nitrifying bacteria. Appl Environ Microbiol. 1995;61:218-21.

12. Chang WS, Li X, Halverson $L$. Influence of water limitation on endogenous oxidative stress and cell death within unsaturated Pseudomonas putida biofilms. Environ Microbiol. 2009;11:1482-92.

13. Imlay JA. The molecular mechanisms and physiological consequences of oxidative stress: Lessons from a model bacterium. Nat Rev Microbiol. 2013:11:443-54.

14. Pomposiello PJ, Demple B. Redox-operated genetic switches: the SoxR and OxyR transcription factors. Trends Biotechnol. 2001;19:109-14.

15. Dubbs JM, Mongkolsuk S. Peroxiredoxins in bacterial antioxidant defense. Subcell Biochem. 2007:44:143-93.

16. Kim J, Jeon CO, Park W. Dual regulation of zwf-1 by both 2-keto-3-deoxy-6phosphogluconate and oxidative stress in Pseudomonas putida. Microbiology. 2008;154:3905-16.

17. Mailloux RJ, Lemire J, Appanna VD. Metabolic networks to combat oxidative stress in Pseudomonas fluorescens. Antonie Van Leeuwenhoek. 2011;99:433-42.

18. Singh R, Lemire J, Mailloux RJ, Appanna VD. A novel strategy involved anti-oxidative defense: The conversion of NADH into NADPH by a metabolic network. PLoS One. 2008;3:e2682.

19. Imlay JI, Linn S. Mutagenesis and stress responses induced in Eschericha coli by hydrogen peroxide. J Bacteriol. 1987;169:2967-76.

20. Tarassova K, Tegova R, Tover A, Teras R, Tark M, Saumaa S, et al. Elevated mutation frequency in surviving populations of carbon-starved rpos-deficient Pseudomonas putida is caused by reduced expression of superoxide dismutase and catalase. J Bacteriol. 2009;191:3604-14. 
21. Gülez G, Dechesne A, Workman CT, Smets BF. Transcriptome dynamics of Pseudomonas putida KT2440 under water stress. Appl Environ Microbiol. 2012;78:676-83.

22. van de Mortel M, Halverson LJ. Cell envelope components contributing to biofilm growth and survival of Pseudomonas putida in low-water-content habitats. Mol Microbiol. 2004;52:735-50.

23. Sies H. Oxidative stress: oxidants and antioxidants. Exp Physiol. 1997;82:291-5.

24. Abella M, Erill I, Jara M, Mazón G, Campy S, Barbé J. Widespread distribution of a lexA-regulated DNA damage-inducible multiple gene cassette in the Proteobacteria phylum. Mol Microbiol. 2004;64:212-22.

25. Abella M, Campoy S, Erill I, Rojo F, Barbé J. Cohabitation of two different lexA regulons in Pseudomonas putida. J Bacteriol. 2007;189:8855-62.

26. Pérez-Pantoja D, Nikel PI, Chavarría M, de Lorenzo V. Endogenous stress caused by faulty oxidation reactions fosters evolution of 2,4-dinitrotoluenedegrading bacteria. PLoS Genet. 2013;9:e1003764.

27. Tenaillon O, Denamur E, Matic I. Evolutionary significance of stress-induced mutagenesis in bacteria. Trends Microbiol. 2004;12:264-70.

28. McMahon MAS, XU J, Moore JE, Blair IS, McDowell DA. Environmental stress and antibiotic resistance in food-related pathogens. Appl Environ Microbiol. 2007;73:211-7

29. de Lorenzo V. From the selfish gene to selfish metabolism: Revisiting the central dogma. BioEssays. 2014;36:226-35.

30. Cytryn EJ, Sangurdekar DP, Streeter JG, Franck WL, Chang WS, Stacey G, et al. Transcriptional and physiological responses of Bradyrhizobium japonicum to desiccation-induced stress. J Bacteriol. 2007:189:6751-62.

31. Johnson DR, Coronado E, Moreno-Forero SK, Heipieper HJ, van der Meer J. Transcriptome and membrane fatty acid analyses reveal different strategies for responding to permeating and non-permeating solutes in the bacterium Sphingomonas wittichii. BMC Microbiol. 2011;11:250.

32. Wang D, Bodovitz S. Single cell analysis: the new frontier in 'omics'. Trends Biotechnol. 2010;28:281-90.

33. Lidstrom ME, Konopka MC. The role of physiological heterogeneity in microbial population behavior. Nat Chem Biol. 2010;6:705-12.

34. Nikel PI, Silva-Rocha R, Benedetti I, de Lorenzo V. The private life of environmental bacteria: Pollutant biodegradation at the single cell level. Environ Microbiol. 2014;16:628-42.

35. Veening JW, Smits WK, Kuipers OP. Bistability, epigenetics, and bet-hedging in bacteria. Annu Rev Microbiol. 2008:62:193-210.

36. Silva-Rocha R, Martínez-García E, Calles B, Chavarría M, Arce-Rodríguez A, de las Heras A, et al. The Standard European Vector Architecture (SEVA): a coherent platform for the analysis and deployment of complex prokaryotic phenotypes. Nucleic Acids Res. 2013;41:666-75.

37. Chang WS, van de Mortel M, Nielsen L, Nino de Guzman G, Li X, Halverson L. Alginate production by Pseudomonas putida creates a hydrated microenvironment and contributes to biofilm architecture and stress tolerance under water-limiting conditions. J Bacteriol. 2007;189:8290-9.

38. Halverson $L$, Firestone MK. Differential effects of permeating and nonpermeating solutes on the fatty acid composition of Pseudomonas putida. Appl Environ Microbiol. 2000;66:2414-21.

39. França $M B$, Panek $A D$, Eleutherio ECA. Oxidative stress and its effects during dehydration. Com Biochem Phys A. 2007:146:621-31.

40. Leprince $\mathrm{O}$, Atherton NM, Deltour R, Hendry G. The involvement of respiration in free radical processes duting loss of desiccation tolerance in germinating Zea mays (an electron paramagnetic resonance study). Plant Physiol. 1994;104:1333-9.

41. Shirkey B, Kovarcik DP, Wright DJ, Wilmoth G, Prickett TF, Helm RF, et al. Active Fe-containing superoxide dismutase and abundant sodF mRNA in Nostoc commune (Cyanobacteria) after years of desiccation. J Bacteriol. 2000;182:189-97.

42. Sikora AE, Beyhan S, Bagdasarian M, Yildiz FH, Sandkvist M. Cell envelope perturbation induces oxidative stress and changes in iron homeostasis in Vibrio cholera. J Bacteriol. 2009;191:5398-408.

43. Motta TB, Sechi AM. Phospholipid polar heads affect the generation of oxygen active species by Fe2+ autooxidation. Biochem Int. 1992;26:987-94.

44. Jin H, Retallack DM, Stelman SJ, Hershberger CD, Ramseier T. Characterization of the SOS response of Pseudomonas fluorescens strain DC206 using whole-genome transcript analysis. FEMS Microbiol Lett. 2007:269:256-64.

45. Kivisaar M. Mechanisms of stationary-phase mutagenesis in bacteria: Mutational processes in pseudomonads. FEMS Microbiol Lett. 2010;312:1-14.

46. Hishinuma S, Yuki M, Fujimura M, Fukumori F. OxyR regulated the expression of two major catalases, KatA and KatB, along with peroxiredoxin, AhpC in Pseudomonas putida. Environ Microbiol. 2006;8:2115-24.
47. Kim J, Park W. Oxidative stress response in Pseudomonas putida. Appl Microbiol Biotechnol. 2014;98:6933-46.

48. Imlay JA. Cellular defenses against superoxide and hydrogen peroxide. Annu Rev Biochem. 2008:77:755-76.

49. Lesniak J, Barton WA. Structural and functional features of the Escherichia coli hydroperoxide resistance protein OsmC. Protein Sci. 2003:12:2838-43.

50. Atichartpongkul S, Loprasert S, Vattanaviboon P, Whangsuk W, Helmann DH, Mongkolsuk S. Bacterial Ohr and OsmC paralogues define two protein families with distinct functions and patterns of expression. Microbiology. 2001;147:1775-82

51. Bjedov I, Tenaillon O, Gérard B, Souza V, Denamur E, Radman M, et al. Stress-induced mutagenesis in bacteria. Science. 2003;300:1404-9.

52. Boles BR, Singh PK. Endogenous oxidative stress produces diversity and adaptability in biofilm communities. Proc Natl Acad Sci U S A. 2008;105:12503-8

53. LeBlanc JC, Gonçalves ER, Mohn WW. Global response to desiccation stress in the soil actinomycete Rhodococcus jostii RHA1. Appl Environ Microbiol. 2008;74:2627-36

54. Erill I, Campoy S, Barbé J. Aeons of distress: An evolutionary perspective on the bacterial SOS response. FEMS Microbiol Rev. 2007;31:637-56.

55. Martínez-García E, Jatsenko T, Kivisaar M, de Lorenzo V. Freeing Pseudomonas putida KT2440 of its proviral load strengthens endurance to environmental stresses. Environ Microbiol. 2015;17:76-90.

56. Wang $Y$, Morimoto $S$, Ogawa N, Fujii T. A survey of the cellular responses in Pseudomonas putida KT2440 growing in sterilized soil by microarray analysis. FEMS Microbiol Ecol. 2011;78:220-32.

57. Koch B, Worm J, Jensen LE, Hojberg O, Nybroe O. Carbon limitation induces $\sigma^{\mathrm{S}}$-dependent gene expression in Pseudomonas fluorescens in soil. Appl Environ Microbiol. 2001;67:3363-70.

58. Lombardo M, Aponyi I, Rosenberg SM. General stress response regulator RpoS in adaptive mutation and amplification in Escherichia coli. Genetics. 2004;680:669-80.

59. Nicolaisen MH, Bælum J, Jacobsen CS, Sørensen J. Transcription dynamics of the functional tfdA gene during MCPA herbicide degradation by Cupriavidus necator AEO106 (pRO101) in agricultural soil. Environ Microbiol. 2008;10:571-9.

60. Pédelaca JD, Cabantous S, Tran T, Terwilliger TC, Waldo GS. Engineering and characterization of a superfolder green fluorescent protein. Nat Biotechnol. 2005;24:79-88.

61. Bao Y, Lies DP, Fu H, Roberts GP. An improved Tn7-based system for the single-copy insertion of cloned genes into chromosomes of Gram-negative bacteria. Gene. 1991;109:167-8.

62. Koch B, Jensen LE, Nybroe O. A panel of Tn7-based vectors for insertion of the gfp marker gene or for delivery of cloned DNA into Gram-negative bacteria at a neutral chromosomal site. J Microbiol Methods. 2001;45:187-95.

63. De Roy K, Clement L, Thas O, Wang Y, Boon N. Flow cytometry for fast microbial community fingerprinting. Water Res. 2012;46:907-19.

\section{Submit your next manuscript to BioMed Central and take full advantage of:}

- Convenient online submission

- Thorough peer review

- No space constraints or color figure charges

- Immediate publication on acceptance

- Inclusion in PubMed, CAS, Scopus and Google Scholar

- Research which is freely available for redistribution 